\title{
The Use of a Memokath Prostatic Stent for Obstructive Voiding Symptoms after Brachytherapy
}

\author{
G. W. de Graaf ${ }^{a} \quad$ P.E.F. Stijns ${ }^{a} \quad$ W.A. Scheepens ${ }^{a}$ \\ $\begin{array}{ll}\text { R.J.A. van Moorselaar } & \text { A. J. M. Hendrikx }{ }^{\mathrm{a}}\end{array}$
}

aDepartment of Urology, Catharina Hospital Eindhoven, Eindhoven; ${ }^{b}$ Department of Urology, Free University Medical Centre, Amsterdam, The Netherlands

\section{Key Words}

Brachytherapy • Obstructive voiding symptoms •

Prostate $\cdot$ Prostatic outflow obstruction • Quality of life •

Stent $\cdot$ Urinary retention provides a safe, effective, and completely reversible treatment for patients with OVS after brachytherapy and was well tolerated.

Copyright $\odot 2013$ S. Karger AG, Basel

\begin{abstract}
Introduction: Brachytherapy may be complicated by serious obstructive voiding symptoms (OVS). Only conservative treatment options are available in the first 6 months after brachytherapy. We evaluated safety, efficacy and patient tolerance of the Memokath prostatic stent (MPS). Material and Methods: A MPS was placed in 10 patients with OVS after brachytherapy. Evaluation included uroflowmetry, international prostate symptom score (IPSS), prostate volume and urethrocystoscopy before and 3 months after placement of the stent. Results: Both the IPSS and uroflowmetry results significantly improved after stent insertion. The mean IPSS decreased from 29/5 to 11/1 and the mean Qmax from the uroflowmetry improved from 4.7 to $11.2 \mathrm{ml} / \mathrm{s}$. The 5 patients who were catheter dependent voided spontaneously with a mean Qmax of $15 \mathrm{ml} / \mathrm{s}$. Two stents migrated towards the bladder, and those patients needed a second stent which was placed without complications. Removal of the stent was easy to perform. Adverse effects were minor with perineal pain and irritative voiding symptoms occurring in 5 patients mainly in the first weeks after insertion. This did not negatively influence quality of life and all patients were more satisfied with the stent than without. Conclusions: The MPS
\end{abstract}

\section{KARGER}

Fax +4161306 1234

E-Mail karger@karger.ch

www.karger.com
(C) 2013 S. Karger AG, Basel

1015-9770/13/0071-0019\$26.00/0

Accessible online at:

www.karger.com/cur

\section{Introduction}

Brachytherapy as a curative treatment option for prostate cancer is still gaining interest, and the number of patients treated with brachytherapy is increasing [1].

Brachytherapy is complicated in $30-50 \%$ by obstructive voiding symptoms (OVS) within 12 months after brachytherapy $[2,3]$. OVS can be quantified using the international prostate symptom score (IPSS) [4]. Also a decrease in the urinary flow curve $[4,5]$ and loss of quality of life [3] can be observed. Approximately $15 \%$ of the patients develop severe OVS and the incidence rate of urinary retention varies from 0 to $36 \%$ [4, 6-10]. In the patients with persisting OVS, an alpha-blocker, (clean intermittent) catheterisation or a transurethral resection of the prostate (TURP) can be a therapeutic option. A TURP is not advised within 6 months after brachytherapy, because this can result in inadequate radiation dosages and side effects.

Since the early eighties prostate stents have been used to treat lower urinary tract symptoms mainly for benign prostate hyperplasia (BPH) in patients less suitable for surgery $[11,14]$. Later they were also used for bladder 
outflow obstruction, external detrusor sphincter dysynergia, urethral strictures, and prostate cancer [11-16]. Overall $10-49 \%$ of the stents placed for BPH had to be removed because of side effects [16], such as migration, voiding symptoms (especially urgency), perineal pain and encrustation $[17,18]$. Due to adhesion to the epithelium of the urethra, patients can develop voiding difficulties and pain after removal of the stent [17].

The Memokath prostatic stent (MPS) (PNN Medical A/S, Danmark) was developed in 1992 [19]. The Memokath $^{\mathrm{TM}} 028$ prostatic stent is a thermo-expandable nickel-titanium alloy stent. Insertion and removal of the stent is easy and non-invasive. The stent is available in lengths from 30 to $70 \mathrm{~mm}$ and can be placed with flexible or rigid cystoscopy.

It was claimed that this stent is easy to insert and to remove, and the tight spiral structure prevents urothelial adhesions. A review of the MPS for BPH showed good results, comparable with TURP [19] and showed that it might be a new and useful tool for OVS. The MPS was placed in 839 men with BPH at high operative risk. All studies reported an increased urinary flow and reduction of IPSS after stent insertion. No major complications were described, only minor complications such as hematuria and infection. In 4\% there was an unsuccessful initial insertion. All stents could be easily removed if necessary.

This current study focuses on treatment of OVS for the time that the brachytherapy seeds are active. The study evaluates the efficacy, safety and patient tolerance of the MPS. To our knowledge it is the first trial using this stent for this indication.

\section{Material and Methods}

In 2008, 10 patients underwent placement of a MPS because of OVS within the first 6 months after brachytherapy. OVS was defined as Qmax $<10 \mathrm{ml} / \mathrm{s}$ and IPSS $>16$ [20]. All patients were seen in the outpatient clinic after brachytherapy. The kind of brachytherapy used was low dose radiation and loose seeds [21]. All patients with a Qmax $<10 \mathrm{ml} / \mathrm{s}$ and IPSS $>16$ or a retention bladder were included in the study for the placement of the MPS. All patients were refractory to more conservative treatment with an alpha-blockers and anticholinergic agents. Patients who developed urinary retention post-brachytherapy were catheterized before placement of the stent.

After informed consent, baseline data was obtained. These include the IPSS questionnaire [22], uroflowmetry including measurement of residual urine, urethrocystoscopy and prostate volume, measured with transrectal ultrasonography.

The IPSS is presented by using a combination of 2 numbers. Taking 29/5 as an example, the first score (29) is the cumulative number of the questionnaire, and the second number (5) indicates the Quality of Life score.

Placement of the MPS was performed under spinal or general anesthesia, by one urologist (AJMH). First an urethrocystoscopy was performed to measure the length of the prostatic urethra. The second step was to place the stent in the correct position: the proximal end at the level of the bladder neck and the distal end just proximal to the external urethral sphincter. The stent was then flushed with hot water of $60^{\circ} \mathrm{C}$. This caused the distal end of the stent to expand in a cone shape, thereby locking the stent.

Patients were checked for residual urine after voiding postoperatively. Intermittent catheterisation was performed when necessary with a Charriére 8 catheter. Patients were discharged from hospital if residual urine was measured to be less than $100 \mathrm{ml}$ by bladder scan.

Follow-up data were obtained at 3 months after stent placement. These include the IPSS questionnaire, uroflowmetry including measurement of residual urine and urethrocystoscopy. Urethrocystoscopy was performed to evaluate the position of the stents and possible encrustation. Baseline and follow-up data were analysed using the Wilcoxon signed rank test.

For the data analysis the Statistical Package for the Social Sciences version 16.0. was used. A difference with a p-value $<0.05$ was considered to indicate statistical significance.

\section{Results}

Ten patients with a T1c-T2b prostate carcinoma were included in the study. The mean prostate specific antigen was 9.9, Gleason sum score ranged from 5 to 7 and prostate volume varied between 36 and $50 \mathrm{ml}$. Five patients were catheterized before stent insertion and 5 were not. The patient characteristics are shown in table 1 .

\section{Efficacy}

The IPSS and Qmax significantly improved after stent placement $(\mathrm{p}<0.05)$ in patients without a catheter.

In the patients without a catheter before stent placement $(n=5)$ the mean IPSS decreased from 29/5 to 11/1 and the uroflowmetry increased from $4.7 \mathrm{ml} / \mathrm{s}$ to 11.2 $\mathrm{ml} / \mathrm{s}$ after 3 months (table 2).

All patients with a catheter before stent placement $(\mathrm{n}=5)$ voided spontaneously with a mean Qmax of 15 $\mathrm{ml} / \mathrm{s}$ after stent placement.

For obvious reasons flowmetry and IPSS were not available before stent placement, due to the catheter. The quality of life score of the IPSS was measured afterwards. These results are summarised in table 3.

\section{Safety}

Two stents migrated towards the bladder within 2 days after placement. In these patients, a second stent was placed without complications. In 1 patient, the stent 
Table 1. Patient characteristics

\begin{tabular}{rrllll}
\hline Patient & PSA & TNM & Gleason & Prostate volume (ml) \\
\hline 1 & 7.7 & T1cN0M0 & 6 & 48 & no \\
2 & 15.0 & T2bNOM0 & 6 & 51 & yes \\
3 & 17.6 & T2bN0M0 & 6 & 68 & no \\
4 & 4.0 & T2aN0M0 & 6 & 39 & yes \\
5 & 9.5 & T1cN0M0 & 6 & 50 & no \\
6 & 9.6 & T2aN0M0 & 7 & 25 & no \\
7 & 7.2 & T1cN0M0 & 6 & 63 & yes \\
8 & 11.9 & T1cN0M0 & 5 & 38 & yes \\
9 & 5.4 & T1cN0M0 & 5 & 45 & yes \\
10 & 11.3 & T1cN0M0 & 7 & 36 & \\
\hline
\end{tabular}

PSA $=$ Prostate specific antigen.

Table 2. Outcome results without catheter

\begin{tabular}{lll}
\hline & Before stent (without catheter) $(\mathrm{n}=5)$ & After 3 months \\
\hline IPSS & $29 / 5$ & $11 / 1$ \\
Uroflowmetry (Qmax) & $4.7 \mathrm{ml} / \mathrm{s}$ & $11.2 \mathrm{ml} / \mathrm{s}$ \\
\hline
\end{tabular}

Table 3. Outcome results with catheter

\begin{tabular}{llr}
\hline & Before stent (with catheter) $(\mathrm{n}=5)$ & After 3 months \\
\hline IPSS & - & $10 / 2$ \\
Uroflowmetry (Qmax) & - & $15 \mathrm{ml} / \mathrm{s}$
\end{tabular}

again migrated, and this patient underwent a TURP, 6 months after brachytherapy. In this patient the urethra prostatica was too tight for stent placement.

Late complications were minor. Five patients reported perineal pain and irritative voiding symptoms especially within the first 6 weeks after treatment. One urinary tract infection was reported, and treated with a course of antibiotics.

\section{Patient Tolerance}

Nine patients with a permanent stent implant reported that they were more satisfied with the stent than without, which was also shown in the quality of life number of the IPSS (fig. 1). The patient in whom stent placement was not possible was not satisfied. This is the second patient in table 1 and figure 1.

After 6 months we made the decision to remove the stent in 4 patients due to minor irritative symptoms and

Curr Urol 2013;7:19-23 


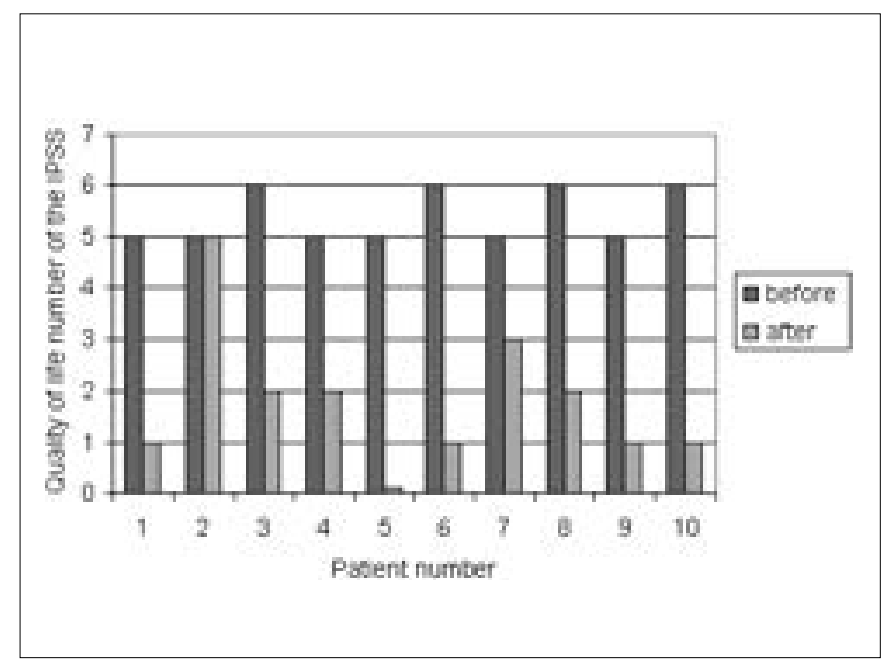

Fig. 1. Quality of life before and after stent placement

to evaluate micturition after removal. These patients were more satisfied with the stent than without, as shown in the quality of life score (fig. 1). The minor irritative symptoms were less than symptoms before stent placement. Stent removal was extremely easy and was performed under spinal or general anaesthesia. During urethrocystoscopy the distal end of the stent was grabbed with a grasper and the stent was flushed with ice water. This caused the stent to become flexible, so it could easily be pulled out of the urethra. In the other patients $(\mathrm{n}=$ 6) there were no complaints and they choose not to have their stent removed. We decided to leave the stent inside and to observe the long-term results.

In the patients who had the stent removed we performed an urethrocystoscopy 3 months after removal. In two the imprint of the stent was still clearly visible in the prostatic urethra and the epithelium showed no abnormalities. These patients had the following Qmax after removal of the stent: 19.5 and $15.3 \mathrm{ml} / \mathrm{s}$. The other 2 patients (including the patient where stent placement was not possible) needed a TURP afterwards.

Adverse events due to stent placement were minimal and all were temporary, no patient suffered permanent damage due to stent placement.

In the patients in whom the stent was still in place after 6 months, the prostatic urethra and the epithelium showed no abnormalities and no encrustation was seen on urethrocystoscopy.

\section{Discussion}

In the current study we evaluated the efficacy, safety and patient tolerance of the MPS in patients with OVS after brachytherapy. Treatment of OVS after brachytherapy can be very challenging. In the first 6 months after brachytherapy, only conservative options are available. After 6 months treatment of OVS with a TURP can cause serious and permanent adverse events, such as incontinence, strictures and even fistulas [23-25]. Our results showed that the IPSS and Qmax significantly improved after placement of the MPS (table 2, 3), without any major adverse events. Catheter dependent patients also voided spontaneously after placement of the stent. Nine out of 10 patients were more satisfied with the stent than prior to stent placement. The most advantageous issue of stent usage is that no permanent adverse events are caused, and stent removal is extremely easy to perform.

To our knowledge this is the first trial using the Memokath stent in patients with OVS after brachytherapy. Other stent types have been used for BPH, detrusor sphincter dysynergia, urethral strictures and prostate cancer [11-16]. In previous studies, using different stents, $10-49 \%$ of stents had to be removed because of major side effects [16]. Migration, voiding symptoms and encrustation encompassed the largest portion of difficulties in the earlier described stents. In this study, we found no encrustation in any of the stents, although we are aware of the short follow-up time.

Unfavourable voiding symptoms have been found in this study. However, these were minor and no stents had to be removed due to major side effects, as described in previous studies with other stents. A possible explanation for these promising results is that in contrast to other stents, urothelial ingrowth does not occur when the MPS is used. This results in a lower percentage of patients experiencing voiding problems. Some voiding problems were reported, but all patients included in the present study had less voiding problems after placement of the stent than before according to the IPSS and flowmetry. A second advantage of the lack of urothelial ingrowth is that the MPS can be removed without damage to the epithelium. In case the patient is not satisfied with the stent, it can be removed without further damage.

Two stents migrated towards the bladder. One was the first placed stent, possibly due to the learning curve. In the other patient the prostatic urethra was too tight to use a stent, so it was not caused by the stent placement itself.

Our results are comparable with the results of a review of the Memokath stent used for BPH [19]. No ma- 
jor complications were described. The IPSS significantly decreased and the uroflowmetry increased. The stent was easy to remove if necessary.

The question that remains to be answered is how long we need to keep the stent in place in patients with OVS after brachytherapy. Previous studies concerning the MPS showed that the stent can remain in situ for years in patients with BPH [12]. This study shows that the MPS is possibly an attractive alternative to TURP after brachytherapy, but larger prospective studies are needed to confirm the use of the MPS for OVS after brachytherapy and to investigate whether the MPS can also be used in the long term as an alternative for a TURP.

In conclusion, this study showed that the MPS can be an attractive, safe and completely reversible alternative for using a catheter the first 6 months after brachytherapy. Although of small sample size, this is the first study to describe the use of a MPS after brachytherapy. These favourable results should be confirmed in a larger study.

\section{References}

$\checkmark 1$ Cooperberg MR, Moul JW, Carroll PR: The $\$ 10$ Sherertz T, Wallner K, Wang H, Sutlief S, changing face of prostate cancer. J Clin Oncol 2005;23:8146-8151.

2 Stone NN, Stock RG: Complications following permanent prostate brachytherapy. Eur Urol 2002;41:427-433.

3 Van Gellekom MP, Moerland MA, Van Vulpen M, Wijrdeman HK, Battermann JJ: Quality of life of patients after permanent prostate brachytherapy in relation to dosimetry. Int $\mathrm{J}$ Radiat Oncol Biol Phys 2005;63:772-780.

4 Williams SG, Millar JL, Duchesne GM, Dally MJ, Royce PL, Snow RM: Factors predicting for urinary morbidity following 125 -iodine transperineal prostate brachytherapy. Radiother Oncol 2004;73:33-38.

5 Wehle MJ, Lisson SW, Buskirk SJ, Broderick GA, Young PR, Igel TC: Prediction genitourinary tract morbidity after brachytherapy for prostate adenocarcinoma. Mayo Clin Proc 2004;79:314-317.

6 Keyes M, Schellenberg D, Moravan V, McKenzie M, Agranovich A, Pickles T, Wu J, Liu M, Bucci J, Morris WJ: Decline in urinary retention incidence in 805 patients after prostate brachytherapy: the effect of learning curve? Int J Radiat Oncol Biol Phys 2006;64: 825-834.

7 Crook J, McLean M, Catton C, Yeung I, Tsihlias J, Pintilie M: Factors influencing risk of acute urinary retention after TRUS-guided permanent prostate seed implantation. Int $\mathrm{J}$ Radiat Oncol Biol Phys 2002;52:453-460.

-8 Niehaus A, Merrick GS, Butler WM, Wallner KE, Allen ZA, Galbreath RW, Adamovich $\mathrm{E}$ : The influence of isotope and prostate volume on urinary morbidity after prostate brachytherapy. Int J Radiat Oncol Biol Phys 2006; 64:136-143.

-9 Mallick S, Azzouzi R, Cormier L, Peiffert D, Mangin PH: Urinary morbidity after 125I brachytherapy of the prostate. BJU Int 2003; 92:555-558.

Memokath Prostatic Stent for Voiding Symptoms after Brachytherapy Russell K: Long-term urinary function after transperineal brachytherapy for patients with large prostate glands. Int J Radiat Oncol Biol Phys 2001;51:1241-1245.

11 Fabian KM: The intra-prostatic "partial catheter' (urological spiral). Urologe A 1980;19: 236-238.

12 Perry MJ, Roodhouse AJ, Gidlow AB, Spicer TG, Ellis BW: Thermo-expandable intraprostatic stents in bladder outlet obstruction: an 8-year study. BJU Int 2002:90:216-223.

13 Oesterling JE, Kaplan SA, Epstein HB, Defalco AJ, Reddy PK, Chancellor MB: The North American experience with the UroLume endoprothesis as a treatment for benign prostatic hyperplasia: long term results. The North American UroLume Study Group. Urology 1994:44:353-362.

14 Badlani GH, Press SM, Defalco A, Oesterling JE, Smith AD: UroLume endourethral prosthesis for the treatment of urethral stricture disease: long term results of the North American Multicenter UroLume Trial. Urology 1995:45:846-656.

15 Juma S, Niku SD, Brodak PP, Joseph AC: Urolume urethral wallstent in the treatment of detrusor sphincter dyssynergia. Paraplegia 1994:32:616-621.

16 Armitage JN, Cathcart PJ, Rashidian A, De Nigris E, Emberton M, van der Meulen JH: Epithelializing stent for benign prostatic hyperplasia: a systematic review of the literature. J Urol 2007;177:1619-1624.

17 Bajoria S, Agarwal SA, White R, Zafar F, Williams G: Experience with the second generation UroLume prostatic stent. Br J Urol 1995:75:325-327.

18 Masood S, Djaladat H, Kouriefs C, Keen M, Palmer JH: The 12-year outcome analysis of an endourethral wallstent for treating benign prostatic hyperplasia. BJU Int 2004;94:12711274.
19 Armitage JN, Rashidian A, Cathcart PJ, Emberton M, van der Meulen JH: The thermo-expandable metallic stent for managing benign prostatic hyperplasia: a systematic review. BJU Int 2006:98:806-810.

20 Porru D, Jallous H, Cavalli V, Sallusto F, Rovereto B: Prognostic value of a combination of IPSS, flow rate and residual urine volume compared to pressure-flow studies in the preoperative evaluation of symptomatic BPH. Eur Urol 2002;41:246-249.

21 Meijer GJ, van den Berg HA, Hurkmans CW, Stijns PE, Weterings JH: Dosimetric comparison of interactive planned and dynamic dose calculated prostate seed brachytherapy. Radiother Oncol 2006;80:378-384.

22 Cockett ATK, Khoury S, Aso Y, Chatelain C, Denis L, Griffiths K, Murphy G (eds): The 2nd International Consultation on Benign Prostatic Hyperplasia. Channel Island, Scientific Communication International Ltd, 1994, pp624-631.

23 Merrick GS, Butler WM, Wallner KE, Galbreath RW: Effect of transurethral resection on urinary quality of life after permanent prostate brachytherapy. Int $\mathrm{J}$ Radiat Oncol Biol Phys 2004;58:81-88.

24 Kollmeier MA, Stock RG, Cesaretti J, Stone $\mathrm{NN}$ : Urinary morbidity and incontinence following transurethral resection of the prostate after brachytherapy. J Urol 2005;173:808812.

25 Chrouser KL, Leibovich BC, Sweat SD, Larson DW, Davis BJ, Tran NV, Zincke H, Blute ML: Urinary fistulas following external radiation or permanent brachytherapy for the treatment of prostate cancer. J Urol 2005; 173:1953-1957. 